\title{
The Model of a System for Criteria-Based Assessing of Students' Functional Literacy and its Developmental Impact
}

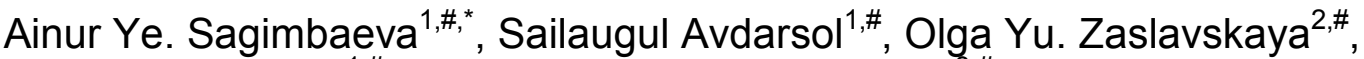 \\ Gulnar S. Arynova ${ }^{1, \#}$ and Aigerim S. Baimakhanova, \\ ${ }^{1}$ Abai Kazakh National Pedagogical University, Almaty, Republic of Kazakhstan \\ ${ }^{2}$ Moscow City Pedagogical University, Moscow, Russian Federation \\ ${ }^{3}$ Khoja Akhmet Yassawi International Kazakh-Turkish University, Turkistan, Republic of Kazakhstan
}

\begin{abstract}
Objective: The purpose of this article is to compile a model of a system for assessing students' functional literacy based on a criteria-based approach.

Background: Everyone use a traditional five-point grading system to assess students' activities, but using it, it's not always possible to objectively evaluate student work. Therefore, the authors use the criteria-based student assessment system in our lessons.

Method: Criteria based assessment involves a mechanism that allows evaluating students more objectively. Assessing the activities of students in the lesson becomes democratic, since a student is the subject of his training, and a teacher does not play the role of a "judge" in grading.

Results: As a result of the study, it was revealed that the assessment system makes it possible to determine how successfully one or another educational material is mastered, or a certain practical skill is formed. At the same time, it is advisable to take a mandatory minimum as a reference point.

Conclusion: The criteria-based assessment system is completely transparent in the sense of how to give formative and summative grades, as well as the goals for which these grades are put. It is also a means of diagnosing learning problems, providing and ensuring constant contact between a teacher, student, and parents. Based on the conducted practical experiment, the effectiveness of the model of the system for assessing the functional literacy of students based on the criteria-based approach in computer science has been proved.
\end{abstract}

Keywords: Criteria-based assessment, student success rate, computer literacy, self-assessment procedures, integrated information.

\section{INTRODUCTION}

One of the most important tasks of a modern school is the formation of functionally literate people. What is functional literacy? Functional literacy is a person's ability to enter into relations with the environment, quickly adapt, and function in it. The foundations of functional literacy are laid in elementary school. A functionally literate person is a person that is orientated in the world and acts in accordance with social values; capable of being independent in a situation of choice and decision making; capable of answering for their decisions; capable of bearing responsibility for themself and their loved ones; easily adaptable in any society and capable of actively influencing it; well versed in oral and written speech as a means of interaction between people; owning modern information technology [1]. Most students with limited health capacities (LHC) have an insufficient level of cognitive activity, immaturity of motivation for learning activities, a reduced level of

*Address correspondence to this author at the Abai Kazakh National Pedagogical University, Almaty, Republic of Kazakhstan; Tel: +77272915768;

E-mail: sagimbaeva5458@ust-hk.com.cn

"These authors are equally contributed. performance and independence. Therefore, the search and use of active forms, methods, and teaching methods are one of the necessary means to increase the effectiveness of the correctional development process in the work of a teacher. When selecting the content of classes for students with disabilities, it is necessary to take into consideration, on the one hand, the principle of accessibility, and, on the other hand, not to allow excessive simplification of the material. For the effective education of children with disabilities, it is important to form a cognitive interest in them, a desire and habit of thinking, an aspiration to learn something new [2].

Using the criteria-based assessment system in schools gives teachers the opportunity to adjust the individual learning path of each individual student with limited health capacities and accordingly improve the quality of education. For a long time, the main approach to assessment was normative, when the individual achievements of students were compared with a certain norm (the results of most students). Recently, a pedagogical approach has been developing a criteria-based approach to assessing 
academic achievement, when students' achievements are compared with the amount of knowledge that needs to be learned at a certain stage of training since there is a need for assessment, the results of which would help to determine which educational goals a particular student has achieved. This led to the advancement of such an aspect of assessment as comparing an individual result with predetermined criteria.

Criteria-based assessment is, according to the definition of A.A. Krasnoborova, is a process-effective meta-technology that provides a system of interconnected controlling-assessing actions of all participants in the educational process to achieve the goals and objectives of training [3]. It differs from the normative-oriented one, in which the work or students are assessed as to how well the work is done by other students. The purpose of criteria-based assessment is to determine and increase the level of students' success by means of criteria allowing to connect the assessment system with the settings indicated as a separate training course, as well as the possibility of building students' competencies at the appropriate educational level. In accordance with this goal, the assessment system itself is aimed at obtaining information that allows students to gain confidence in the successful inclusion in the system of continuing education; parents to observe the development process of their child directly; teachers to judge the effectiveness of a program, the progress, and achievements of students [4].

The authors examined the experience of using criteria-based assessment in lessons by teacher A.S. Suleimenova. She believes that using this system is easier to evaluate the student with limited health capacities when working with projects. Considering the grading system of A.S. Suleimenova, the authors undoubtedly noted positive results. The only thing that is not very convenient here is a large number of grades when adding up. There is no independence of students with limited health capacities in formulating criteria, and also, she did not find methods of mutual assessment. After analysing the development of various authors, the authors came to a conclusion that: the criteria-based assessment tools contain descriptors for evaluating both the educational result and the process of performing practical tasks; at various levels of education, schoolchildren with limited health capacities can be involved in the formulation of criteria, with varying degrees of independence. So, when teaching schoolchildren with limited health capacities, the authors used assessment criteria, both developed by methodologists [5], and developed by them and the students with limited health capacities themselves in the classroom.

The purpose of the paper is to develop a model of a system for assessing the functional literacy of students with limited health capacities based on a criteria-based approach.

\section{MATERIALS AND METHODS}

In determining functional online literacy, the study by $\mathrm{K}$. Dolenc shows that there are differences in reading comprehension when reading offline and online when using electronic school material in their educational process. The study involved 35 students with limited health capacities of 7-11 grades of the gymnasium school No. 200 (Almaty, Republic of Kazakhstan). The authors used individual and adaptive intelligent learning systems (ITS) and, using the assessment of the results, showed that for this form of ITS, there is still enough room for optimisation, which is a constant method of improvement and updating in such systems [6, 7].

The functional literacy of schoolchildren with limited health capacities in lessons is possible through the solution of three main tasks:

- achieving a level of education that meets the potential of a student with limited health capacities and ensures the further development of an individual and the ability to overcome education, including through self-education.

- $\quad$ the formation of experience of each student with limited health capacities of creative socially significant activity in the realisation of their abilities.

- $\quad$ the accumulation of experience of students with limited health capacities in communication and interaction on humanistic relationships.

The six main stages of Bloom's Taxonomy can be seen as a hierarchy of skill and ability, the level of tasks recommended by students with limited health capacities. Here, the word "task" is used in a broad meaning - this is a question that can be a question of a teacher, training, tasks, project, etc. In addition, since training at the levels of "knowledge" and "comprehension" leads to superficial learning, for teachers to develop functional literacy to offer tasks 
that require a high level of thinking - "application", "analysis", "synthesis", and "evaluation".

Thus, the characterisation of taxonomy levels can become an algorithm for the development of developing tasks. It can be said that the operational setting of learning goals is also a prerequisite for organising and conducting developing learning, developing functional literacy of students with limited health capacities, as well as putting into practice a criteria-based system for assessing students with limited health capacities knowledge. Since the training paradigm was chosen as a way of personal activity, the content of each level of the three-dimensional methodological system is formed in the form of the necessary multi-level tasks that develop students' independent cognitive activity. They are: characterisation of the taxonomy of learning objectives; the most important characteristic of the basic properties of the corresponding level; based on the requirements for the development levels of a three-dimensional methodological system.

With the help of this learning technology, three levels of development of the methodological system can be defined. They are as follows:

1st level - reproductive. There should be convenient definitions, concepts, rules, etc., as well as questions, tasks for repeating and working out new knowledge in the previous lesson, that should be effective for a new topic, situational tasks related to life.

2nd level - algorithmic. The use of previously mastered, reproductive, algorithmic effects. Students carry it out independently, using information about previously mastered indicative basics of this activity.

3rd level - creative. Application of previously acquired knowledge and skills for solving atypical tasks. This is a productive activity in which students with limited health capacities or subjective new information (only new to themselves) is a heuristic activity, or when they act "without rules" they create objectively new, but different rules of action in the area in which they know, i.e., conduct research work.

Assessment criteria are developed, taking into account the requirements of a standard for academic discipline, methodological recommendations. The criteria are not absolute; the assessment of similar activities varies with the age of students.

The formation of cognitive interests among students with limited health capacities is carried out in the process of training and education and also includes extracurricular work in academic subjects. The organisation of extracurricular activities contributes to more solid and conscious assimilation of the studied material, promotes the development of students' speech, increases the level of language development of schoolchildren, and fosters interest in the subject. Extracurricular work allows students to apply their knowledge and skills in new, non-standard situations received by children in lessons. In this case, the correct and purposeful organisation of extracurricular activities of students with limited health capacities helps develop the habits of appropriate behaviour in society and work in children, in learning independence and initiative, contribute to further successful socialisation in society. The knowledge and skills acquired by students in the lessons play an important role in preparing children for practical activities in life and, at the same time, contribute to more successful mastery of all subjects in the school course. An integral part of extracurricular activities is that in each of them, students get the opportunity to solve feasible tasks, perform elementary stylistic exercises. This helps to awaken a direct interest in the subject and the desire for knowledge in schoolchildren.

\section{RESULTS}

The criteria-based approach to assessing students with limited health capacities consists of comparing the student's achievements with well-defined, collectively developed criteria well known to all participants in the process. Evaluation criteria are developed for each subject. With proper preparation of the criteria scale, a student with limited health capacities can independently assess the quality of their work, which stimulates the achievement of a higher educational result and the formation of educational independence. The application of the criteria-based approach in the educational system makes it possible to identify and improve the system for assessing student performance with the objective goals of an individual subject, as well as using certain parameters (criteria) that allow students with limited health capacities to compete in high school.

In accordance with modern requirements for correctional education, a basic educational program for primary correctional education is currently being developed. One of the sections of this program is a system for assessing the achievement of the planned results of mastering the main educational program, since if the result is planned, then it is necessary to 
track and evaluate the achievements of students. The system for assessing the achievement of the planned results of mastering the basic educational programme of primary general education (hereinafter - the assessment system) by students with limited health capacities is one of the tools for implementing the Standard Requirements for the development of the basic educational programme of primary general education and is aimed at ensuring the quality of education.

The main object of the assessment system, its substantive and criteria framework, is the planned results of mastering the basic educational program of primary general education. The main functions of the assessment system are the orientation of the educational process towards achieving the planned results of mastering the main educational programme and providing effective feedback. The main results of primary general education: the formation of universal and subject methods of action, as well as a supporting knowledge system, providing the possibility of continuing education in a primary school; the education of the basics of the ability to learn - the ability to fulfil oneself with the purpose of solving educational, practical problems; education of the basics of life competence (social competence); individual progress in the development of the cognitive and emotionalvolitional sphere of activity of primary school children with limited health capacities.

Assessment as a means of ensuring the quality of education supposes the involvement of not only teachers but also students with limited health capacities in the evaluation activity. Evaluation not only enables students with limited health capacities to master elementary effective means of managing their educational activities but also contributes to the development of self-awareness, willingness to express their position, the development of readiness for independent actions and actions.

Distinctive features of the assessment system: an integrated approach to assessing the results of education (assessment of subject, meta-subject, and personal results); the use of the planned results of mastering the basic educational programmes as a meaningful and criteria-based assessment framework; assessment of the success of mastering the content of individual educational subjects based on a systemactivity approach, manifested in the ability to perform educational and practical tasks; assessment of the dynamics of educational achievements of students with limited health capacities; combination of external and internal assessment as a mechanism to ensure the quality of education; use of personalised procedures and non-personalised procedures; tiered approach to the development of planned results, tools, and data presentation; the use of a cumulative assessment system (portfolio), which describes the dynamics of individual educational achievements; use of such assessment methods as practical work, creative work, self-esteem, observation, etc. along with standardised written or oral works; the use of contextual information about the conditions and features of the implementation of educational programs in interpreting the results of pedagogical measurements.

Assessment of the achievement of the planned results of mastering by students with limited health capacities of the main educational programme includes a start, current (formative), and intermediate (final) assessment. The subject of the initial assessment, which is carried out at the beginning of each academic year, is the determination of the residual knowledge and skills of students regarding the past academic year, which allows the teacher to organise the repetition process effectively and determine the effects of training over the past academic year. The subject of the current (formative) assessment constitutes the operational composition of objective modes of action and key competencies. Such an assessment is carried out both by the student and the teacher and performs two important functions: diagnostic and corrective. The purpose of such an assessment is to see the problems and difficulties in the development of substantive methods of action and competences and to outline a work plan to eliminate the problems and difficulties that have emerged. The subject of the intermediate (final) assessment at the end of the school year is the level of development by students of cultural subject ways and means of action, as well as key competencies. The school service for assessing the quality of education (director of studies) carries out such evaluations external to the teacher.

The formative assessment of educational results of students with limited health capacities is carried out in accordance with an agreed approach to the planning and implementation of the educational process for all students throughout the entire period of study. The purpose of this assessment is to identify the strengths and weaknesses of each student, to develop and implement strategies aimed at improving student performance with limited health capacities. Students should have a clear understanding of which sections of 
the programme are growing and what they can do to improve their academic performance. For efficiency purposes, the assessment of the educational results of students with limited health disabilities includes: an indication of the assessment techniques that will be used during the educational process; brief information about the assessment methods that will be used, as well as an indication of when and how it will happen; information on how to provide a differentiated approach to learning, i.e., how the organisation of the class/teaching methods, learning resources and assessment of student knowledge will vary in order to develop the full range of students' abilities; information on how it is supposed to analyse and evaluate the curriculum (including all elements of the assessment process).

The general assessment system is of a layered nature and comprises the following elements: assessment of the subject, personality, and metasubject results based on the results of the school year: basic and minimum necessary (reduced) level. The planned results include the following: personal results, sensemaking, moral and ethical orientation; metasubject results are: regulatory, communicative, cognitive learning activities. Evaluation of substantive results is not difficult, because we observe, monitor, and record the level of knowledge acquisition based on verification, control, and integrated work; assessment of the development of life competences includes the following planned results: the development of ideas about personal capabilities and limitations, mastery of social and household skills, mastery of communication skills, differentiation, and understanding of the picture of the world and their social environment.

\section{DISCUSSION}

Functional literacy is the result of education that provides the skills and knowledge necessary for personal development, obtaining new knowledge and cultural achievements, mastering new technology, successfully fulfilling professional duties, organising family life, including raising children, solving various life problems. V.S. Bezrukova, in the encyclopaedic dictionary of a teacher, defines functional literacy (lat. direction) as the degree of a person's preparedness to perform the functions assigned to him or his voluntarily taken over $[8,9]$. The pedagogical dictionary of L.P. Rusinova indicates that functional literacy is the level of education, characterised by the degree of mastery of the cognitive means of the main types of life; this level is characterised by the ability to solve standard life tasks in various spheres of life based on mainly applied knowledge [10].

The opposite - functional illiteracy, which does not allow a person to understand technical instructions, programs of political parties, and complex tests. M.Yu. Oleshkov defines functional literacy as the level of education, which is characterised by the ability to solve standard life tasks in various spheres of life based on mainly applied knowledge [11]. In the terminological dictionary of a modern teacher, functional literacy is interpreted as the ability of a person to competently, correctly function in all spheres of human activity. Thus, summarising the above, functional literacy becomes a factor facilitating the participation of people in social, cultural, political, and economic activities, the ability to think creatively and find standard solutions, the ability to choose a professional path, be able to use information and communication technologies in various spheres of life, and lifelong learning [11-14].

The expected results of students with limited health capacities given the opportunity to objectively assess their educational achievements and determine their personal development paths, taking into account the abilities of each student with limited health capacities, also contribute to the stimulation of the abilities of students with limited health capacities and expect improvement in the quality of the educational process. The determining factor is the level of compulsory training. Its achievement indicates that a student with limited health capacities has performed the minimum necessary requirements for mastering content. Based on it, higher levels of mastery of material are formed. Recently, this type of differentiation has come to be called level differentiation (in addition to level differentiation, there is also profile differentiation).

Level differentiation (according to E.S. Polat), should be understood such an organisation of an educational process in which each student with limited health capacities has the opportunity to master the educational material at different levels, but not lower than the basic, depending on the desire, abilities and individual characteristics of a person. Moreover, the evaluation criteria are the efforts of a student with limited health capacities to master material and its creative application [13]. The implementation of intraclass level differentiation involves taking into account such features of students with limited health capacities that affect their educational activities and on which the learning outcomes depend [15]. 
The quality of training is the correlation of goals and learning outcomes, while the goal is only operational and accumulated in the nearest student with limited health capacities development zone. That is, training is recognised as high-quality if results meet specified diagnostic goals and cover a potential area of development of a student with limited health capacities. The purpose of the operational (diagnostic) setting of learning goals is characterised by the fact that they are formed using the learning outcomes reflected in the activities of students with limited health capacities, which can be accurately measured and recognised [1618].

In our opinion, and in accordance with the results of the study, the use of active teaching methods and techniques increases the cognitive activity of students, develops their creative abilities, actively involves students in the educational process, stimulates students' independent activity, which equally applies to children with limited health capacities. Active teaching methods provide a solution to educational problems in various aspects: the formation of positive educational motivation; increasing cognitive activity of students; active involvement of students in the educational process; stimulation of independent activity; development of cognitive processes - speech, memory, thinking; effective assimilation of a large amount of educational information; development of creative abilities and thinking outside the box; development of the communicative and emotional sphere of the learner's personality; disclosure of personal and individual capabilities of each student and determination of conditions for their manifestation and development; development of independent mental work skills; universal skills development [19-21].

The variety of existing teaching methods allows the teacher to alternate between different types of work, which constitutes an effective means of enhancing learning. Switching from one type of activity to another protects against overwork, and at the same time, does not distract from the material under study and also ensures its perception from various sides [22].

\section{CONCLUSIONS}

The study of criteria-based assessment as the basis for the formation of functional literacy in students with limited health capacities and the results of experimental work has led to several conclusions:

1. Criteria-based assessment helps reduce the anxiety of students with limited health capacities, form a positive motivation. The fact that grades obtained for intermediate work are not put up in a journal makes this work a meaningful activity to build up knowledge. A teacher is transformed from a severe judge to a concerned assistant and consultant. Between a teacher and a student, the conflict zone disappears, assessment becomes a joint work according to the criteria adopted by both parties.

2. The basic content of education involves objective results aimed at enhancing the functional, including the practical focus of training. Despite the different number of points in the assessment and the divergence of opinions on this issue in different countries, in all of these systems, the unifying core is the criterion of assessment and the differentiation of the levels of assimilation of educational material by students.

3. The process of developing functional literacy in students with limited health capacities with the use of the assignment determines the introduction of a new assessment system that takes into account the effectiveness of all types of educational activities, the procedural side of learning material and the manifestation of individual and personal qualities of students

4. The system of criteria-based assessment using the task of functional literacy allows to receive integral and differentiated information about the educational process, track the individual progress of students in achieving the planned results, provide feedback for teachers, students, and parents, monitor the effectiveness of the educational program.

\section{ACKNOWLEDGEMENT}

None.

\section{REFERENCES}

[1] Vygotsky, LS. Educational psychology. Moscow: AST, 2012.

[2] Amonashvili ShA. Fundamentals of humane pedagogy. In 20 books. Book 4. Moscow: Amrita, 2012.

[3] Krasnoborova AA. Criteria-based assessment as a means of improving the quality of education in the logic of the competency-based approach. Portrait of a student in the focus of International Baccalaureate programs. Education that will make the world a better place. Perm: Perm State Pedagogical University, 2009.

[4] Romanov YuV. Assessment system: the experience of reflection and use. In: MA Pinskaya (Ed.). Formative assessment: classroom assessment. Moscow: Logos $M$ 2010; pp. 177-184 
[5] Demidovich EA. Experience in implementing the competency-based approach to the training of special educators in the secondary vocational education system. Special Education 2011; 3: 98-104.

[6] Sagimbaeva AE, Zaslavskaya OYu, Avdarsol S. Criteriabased approach to the assessment of educational achievements in the Republic of Kazakhstan. In: Collection of the XI International Scientific and Practical Conference Shamovskie pedagogical readings of the scientific school of Educational Systems Management "Modern vectors of educational development: relevant problems and promising solutions". Moscow: Moscow State Pedagogical University 2019; pp. 515-519.

[7] Dolenc K, Aberšek B, Aberšek MK. Online functional literacy, intelligent tutoring systems and science education. Journal of Baltic Science Education 2015; 14(2): 162-171.

[8] Quarstein VA, Peterson PA. Assessment of cooperative learning: a goal-criterion approach. Innovative Higher Education 2001; 26(1): 59-77. https://doi.org/10.1023/A:1010938521365

[9] Bezrukova VS. Fundamentals of spiritual culture (encyclopedic dictionary of a teacher). 2000. Available at: https://studylib.ru/doc/571133/osnovy-duhovnoj-kul._tury.-enciklopedicheskij-slovar._-pedagoga.

[10] Rusinova LP. The pedagogical dictionary by topics. 2010. Available at: https://www.psyoffice.ru/slovar-s181.htm

[11] Oleshkov MYu, Uvarov VM. The modern educational process, basic concepts and terms. Moscow: Kompaniya Sputnik 2006.

[12] Berkimbayev KM, Sarybayeva AKh, Usembayeva IB, Ramankulov ShZh. Teaching of using information and computer technology for preparation of competitive specialists. In: Materials of the II international "Research and practice conference". Westwood: Publishing office Accent Graphics communications 2013; pp. 425-429.

[13] Polat ES, Bukharkina MYu, Moiseeva MV, Petrov AE. New pedagogical and information technologies in the education system. Moscow: "Academia" Publishing Centre, 2001.

[14] Sagimbaeva AE, Avdarsol S. Assessment of students' functional literacy in computer science based on a criteria- based approach. Vestnik-Khabarshy. Series of "Physics and Mathematics" 2019; 4(68): 182-189.

[15] Veriaev AA, Nechunaeva MN, Tatarnikova GV. Functional literacy of students: representations, critical analysis, measurement. News of Altai State University 2013; 2-2(78): 13-17.

https://doi.org/10.14258/izvasu(2013)2.2-01

[16] Badia A, Campos LCh. Teachers learn about student learning assessment through a teacher education process. Studies in Educational Evaluation 2018; 58: 1-7. https://doi.org/10.1016/i.stueduc.2018.05.004

[17] Nikou SA, Economides AA. The impact of paper-based, computer-based and mobile-based self-assessment on students' science motivation and achievement. Computers in Human Behavior 2016; 55: 1241-1248. https://doi.org/10.1016/j.chb.2015.09.025

[18] Sangiorgio V, Uva G, Aiello MA. A multi-criteria-based procedure for the robust definition of algorithms aimed at fast seismic risk assessment of existing RC buildings. Structures 2020; 24: 766-782. https://doi.org/10.1016/j.istruc.2020.01.048

[19] Kilpatrick JR, Wolbers KA. Beyond the red pen: A functional grammar approach to evaluating the written language of deaf students. Psychology in the Schools 2020; 57(3): 459-474. https://doi.org/10.1002/pits.22289

[20] Keizer E. Modelling stance adverbs in grammatical theory: tackling heterogeneity with functional discourse grammar. Language Sciences 2020; 12(7): Article number 101273. https://doi.org/10.1016/j.langsci.2020.101273

[21] Jaakma K, Kiviluoma P. Auto-assessment tools for mechanical computer-aided design education. Heliyon 2019; 5(10): Article number e02622. https://doi.org/10.1016/j.heliyon.2019.e02622

[22] Lipovtcev AY. Pedagogical statistics version 1.0.0 - a program for analysing data obtained as a result of pedagogical research using the statistical criteria of CramerWelch, Wilcoxon-Mann-Whitney, Chi-square and Fisher. Moscow: Nauka, 2004.

DOI: https://doi.org/10.6000/2292-2598.2020.08.03.11

(c) 2020 Sagimbaeva et al.; Licensee Lifescience Global.

This is an open access article licensed under the terms of the Creative Commons Attribution Non-Commercial License (http://creativecommons.org/licenses/by-nc/3.0/) which permits unrestricted, non-commercial use, distribution and reproduction in any medium, provided the work is properly cited. 